\title{
Investigating the Notion of 'Good Practice' in Primary Schools in Cyprus: The Perspective of Teachers and Associate Professionals Working with Pupils with Behaviour Emotional and Social Difficulties
}

\author{
Tryfonos Stella \\ Department of Education, University of Birmingham, UK
}

\begin{abstract}
This paper discusses a study of perceptions of teachers and associated professionals working with pupils with BESD of primary school age in Cyprus and it draws on of a study undertaken in 2007-2009 in a Cypriot primary school which operates under a Priority Education Policy. A qualitative, interpretive approach to data collection was employed combining two different methods: interviews and classroom observations. Discussion focuses upon the factors involved in enhancing good practice in teaching pupils with BESD, how the participants perceive good practice and possible ways to improve the current practice in the future. The findings constitute potentially rich material with pedagogical implications that maybe shown to be crucial in not only shedding light on the nature of the issue under study, but also in suggesting potentially effective practice. Two key themes emerged as the most challenging in addressing difficulties of these pupils is discussed: the role of associate professionals and the time taken for official identification and assessment of the difficulties to be made.
\end{abstract}

\section{Introduction}

Pupils with Behavioural Emotional and Social Difficulties (BESD) present a challenge to teachers, family and professionals working with them, and as research has established, these pupils are the "most negatively stereotyped' and 'the least accepted' (Cooper, [7]; Winzer, [18], p.27). The history of BESD is long and it is marked by an ongoing debate and concern with regard to who these children are and what form of educational provision is suitable for them given their difficulties (DES, [8]; Cole et al, [6]). The complexity, disparity and lack of consistency in characteristics displayed result in further confusion over the identification of pupils with BESD and as once stated by Cole [2]; this was often followed by confusion concerning their placement and provision procedures. Decisions on the education of these children were mainly medically-oriented and as a result of this, children considered with BESD were educated in segregating environments such as in special schools or clinics (DES, [8]). The abolition of 'categorisation' of special educational needs (SEN) by the 1981 Education Act following the recommendations of
Warnock Report in 1978 in relation to the education of pupils with (SEN), marked also a shift away from segregationist and medically-oriented practices towards a more inclusive and child-oriented ones. Meanwhile, the ongoing reports and the concerns of the Education Department in the UK (e.g. the Elton Report, [9]; DfE, [10]; DfES, [12]) let to various improvements with regard to the education of children with BESD. The main focus of the Department of Education in the UK is to help pupils to reach their full potential and to develop an education service which provides 'equality of opportunity and high achievement for all children' (DfE, [12], p.i).

For the Cypriot Education, on the other hand, identification, assessment and provision for children with BESD remains an elusive educational issue without relevant guidance or policy in place to aptly provide a plan for how to identify and effectively address the difficulties of these pupils in school (Angelides [1]). One of the few circulars forwarded to schools by the Cypriot Ministry of Education mentioning the BESD is the 1992 Circular (MOEC) and very briefly providing a definition of behavioural difficulties. Recently, the 2008 National Report on Education (MOEC, [14]) has raised the issue of BESD in schools and stressed the importance of setting a committee and a plan to guide actions under which this issue will be addressed.

Given the complexity of these difficulties and the conditions under which pupils may display BESD; good practice in teaching these pupils involves an approach which is based on building up a receptive, supporting and motivating school milieu. (e.g. Cole, Visser and Upton, [4]; Cooper, [7], Visser, [17], Cole [2]). In light of what has been said, the current study comes in the context of exploring perceptions of teachers and associated professionals working in two schools which are operating under the umbrella of a newly introduced educational policy in Cyprus. The policy is guided by an area-based initiative known as "Priority education policy" and schools operating under the guidelines and principles of "priority education" are called ZEP Schools (Schools within Zones of Educational Priority). Teachers are those who are usually at the demanding end of any new educational policy (Rogers [16]); their perceptions and experience are those which can potentially shape future practices and therefore are considered key 
account to a research that explores experience and perceptions. Various studies in the literature on this issue attach value to the accounts of educators and practitioners; these studies have aided to the establishment of an understanding around the BESD, the impact of effective school and teachers' practices as well as elements contributing to 'good practice' (e.g. Cooper, [7]; Cole et al, [6]; Cole et al, [4]; Cole et al, [5]; Visser, [17]; Rogers, [16]).

The breadth of this study highlights issues associated with how the needs of pupils with BESD are addressed and what processes are in force to support their learning. Despite of this, however, in this article, only part of the findings is discussed and this relates to the procedure in place to identify, evaluate and decide for provision for cases of pupils considered with BESD.

By choosing a case study as the main approach to conducting this research, it was hope to attract a range of prospective audiences including colleagues, teachers, educational officials, and other associated professionals across different educational disciplines. These different audiences may use information for different purposes or for addressing different needs emerging from their work. The wealth of information that can be potentially generated by such an approach it is likely to provide a real contribution to knowledge and engages the audiences mentioned above.

\section{Research Rationale}

The study reported in this paper emerges as part of professional experience, interest and the difficulties I came across while working with pupils with BESD. These pupils' difficulties present challenges to those working with them and and one key question echoed in the work of many researchers in the literature seems to revolve around finding "the most efficient approach: "What is the most efficient approach to address the needs of the pupils and work with them effectively"?

To this end this study brings to the fore two important apprehensions which have been at the heart of attention for many educators and professionals working with pupils with BESD (i.e. DES, [9]; MOEC, [14]; DfE, [10]; DfE, [11]; Cole, Visser and Upton, [4]; Angelides [1]; Visser, [17]). The first one concerns the mainstream school provision and how effective the school practices when working with these pupils; and the second concerns the perceptions of those people working with these pupils (teachers and associated professionals). Considering the potential benefits that this research could bring to the audience-educators and researchers- who are concerned with this field, the purpose was to gather views with regard to how good practice in working with these pupils is perceived, and outline issues emerging from their perceptions. Furthermore, given that the research is applied to a rather unexplored context of the Cypriot educational system (that is ZEP schools), part of the rationale in undertaking this study is to prompt further research and interest in the context.

\section{Methodology}

The conclusions drawn from the findings of this study were based on a case study of two ZEP Schools and a qualitative interpretive approach for collecting, analyzing and presenting data. For the collection of data 22 interviews (of teachers, headteachers, teaching assistants, educational psychologists) and 29 observations at forty minutes each in both schools were conducted. Additional information was gathered from informal discussions with the headteachers of the two subject schools, including data about the characteristics of the school populations, referrals for assessment, support received by social services and information regarding cases of pupils.

\section{Two emergent themes concerning 'good practice'}

Among the findings, two key themes seem to emerge concerning first the role of associate professionals in building up a collaborative and supportive network for addressing the difficulties and needs displayed by these pupils and second the time taken for official assessment to take place.

Official documents and research reports in the UK, seem to attach value on concerted approach by a well-established network of professionals (DfE, 2001). That is specialist support from Local Educational Authorities (LEAs) departments, educational psychologists (EPs), SEN teachers, and social welfare departments and teacher assistants. Part of what comes in the current study disputes the clarity of the role of all these parties, as well as the efficiency of the services they provide when the schools request their involvement. Similar to the findings of earlier studies (e.g. Cole et al, [5], [6]), teachers in this study seem to regard EPs and SEN teachers, as their most commonly associate partners in addressing the difficulties of students. In addition, while the liaison with EPs emerged as one of the most frequent, external agencies to work with the expressed their concern about the time that is devoted to the school and the cases of pupils that require their support. Moreover it was also stated that the time of EPs is shared between three or four schools. That makes the collaboration between school and EPs more difficult than if the EP was working in the same school on daily basis. Despite that, the teachers reported a number of external agencies who support their work in school; the views 
concerning punctuality and capacity of support provided by these agents seem to be a controversial issue for the respondents who in some cases reported inadequate support. Teachers explain that in many cases the behaviour of pupils is challenging and they do not feel confident to provide support during lesson without having an additional support in the classroom. Furthermore some of the participants expressed their disappointment concerning the support they receive from agents such as the social workers, the EPs, SEN teachers or teaching assistant and claim that there is neither a systematic presence of these people in the school nor clear understanding of their role. Concerning the identification, assessment and decisions for provision procedure, the headteachers interviewed reported that a local multidisciplinary team which is appointed by the LEAs and consist of EPs, SEN teachers, Clinical Psychologist, the teacher, headteacher of the school and the social worker, aims at evaluating cases of pupils with SEN (including pupils with Behaviour difficulties) and setting up a plan with regard to the form and capacity of support the pupil will receive. In describing their collaboration with these agents, the participants claimed that their presence in school is not systematic, in many cases it takes a lot of time between the time a request for an assessment of a case is filed and the time where a decision is reached.

Having said this, the participants of this study were asked, given their experience, to provide their accounts with regard to the procedure to identify assess and provide for the child who is referred to the LEAs for assessment. Given the importance of early identification, assessment and provision for any pupil with SEN to be responsive to the learning support plans, it was expected to receive positive views. However, despite the importance of this process, participants described a rather time-consuming and bureaucratic procedure which takes between 4-13 months. Along these lines the headteachers of the two schools, as well as some of the teachers claim that not only a long time is required from the time a referral is filed to the relevant department of the LEAsto the time a decision is reached but also during this time teachers are working without receiving any professional support. In some cases it takes up to a year for the LEAs and the multidisciplinary team to decide the form of provision or support the pupil will receive and in this case the teacher works with the child based on his/her experience and without guidance.

The majority of the participants seem to believe that achieving good practice in working with pupils with BESD is not a utopian task; however the role of professionals and agents who work in partnership with the school and the time taken to reach a decision with regard to the learning support plan, are issues which are essential for establishing a punctual, efficient support system in school.

\section{Conclusion}

For the purposes of data collection two different research tools were utilized and each one of them examined the issue of study from a different prism. The interviews provided insights from teachers' experiences and perceptions and the observations aided the creation of a picture relating to classroom actions and the learning of these pupils. Interview accounts in some cases seemed to agree with observation findings and in some cases seemed to show a different reality; nevertheless both aided and enhanced my conclusions.

The data collected suggests that teaching pupils with behaviour difficulties can become a stressful process for the classroom teacher especially if no adequate support is received. On the other hand, examples drawn out from this study suggest that the location of the school does not really affect the efficiency of work in teaching these pupils and there is always a potential to develop effective practice. Despite the problematic situation of the context in terms of teaching pupils with behaviour difficulties, the accounts of participants lead to conclude that having practitioners with positive ethos and a professional understanding of the needs of individual pupils and educators who are ready to deliver the aims of vigorous policies and programmes, as well as prompt and efficient professional support are essential elements for realising good practice. Moreover, the findings indicate that a welcoming and well-resourced school and classroom environment are another essential aspect of good practice.

\section{A need for further future research}

Whilst this research endeavoured through exploring the accounts of teachers and associate professionals working with pupils displaying BESD to expand a relatively unexplored field in the Cypriot Educational system, implementing it acknowledged a need for further study of the issue. In order to gain a wider understanding of how difficulties and presented by pupils with BESD are addressed and current practice could be improved, future research must expand on a larger scale sample of schools and teachers and associate professionals. Bearing in mind that progress towards realizing good practice and high standards in working with pupils with BESD is a task requiring the involvement of different actors each of whom could contribute to a different aspect of their learning, future research sufficiently robust is required to explore issues relating to achieving better practice such as school and staff ethos, partnership building between school and professionals and school and families, learning and behaviour support plans, as well as teaching approaches. 


\section{Acknowledgement}

I would like to thank Dr Natasha Macnab who generously gave her time and offered her advice, support and encouragement throughout the writingup of my research, as well as Bader Kurdali who always sees my work and offers patiently his professional advice.

\section{References}

[1] Angelides, P. (2000) A new technique for dealing with behaviour difficulties in Cyprus: the analysis of critical incidents. European Journal of Special Needs Education. Vol. 15(1): pp 55-68.

[2] Cole, T. (2006) "Chapter 31: Patterns of Effective Provision for Pupils with Emotional and Behavioural Difficulties: The English Experience." In: Carsch, H., M., Tiknaz, Y., Cooper, P., Sage, R., (Eds) The Handbook of Social, Emotional and Behavioural Difficulties. London: Sage Publications Ltd.

[3] Cole, T., Sellman, E., Danniels, H., Visser, J. (2001) The mental health needs of pupils with emotional and behavioural difficulties in special schools and pupil referral units. School of Education: University of Birmingham.

[4] Cole, T., Visser, J., Danniels, H. (1999) A model explaining effective EBD practice in mainstream schools. Emotional and Behavioural Difficulties. Vol. 4 (1): p. 1218.

[5] Cole, T., Visser, J., Danniels, H. (2001) "Chapter 12: Inclusive Practice for Pupils With Behavioural Difficulties in Mainstream Schools". In: Visser, J., Danniels, H., Cole, T., (Eds) International Perspectives on Inclusive Education. Volume 1: Emotional and Behavioural Difficulties in Mainstream Schools. London: JAI-An Imprint of Elsevier Science.

[6] Cole, T., Visser, J., Upton, G., (1998) Effective Schooling for Pupils with Emotional and Behavioural Difficulties. London: David Fulton Publishers Ltd.

[7] Cooper, P. (1993) Effective Schools for Disaffected Students: Integration and Segregation. London: Routledge.

[8] DES (1955) Report of the Committee on Maladjusted Children (The Underwood Report). London: Ministry of Education. London: HMSO

[9] DES (1989) Discipline in Schools (Elton Report) London: HMSO [Online]. Available from: http://www.dg.dial.pipex.com/documents/docs1/elton03.sh tml [Accessed 30/03/09]

[10] DfE (1994a) Pupils with problems-Pupil Behaviour Discipline. Circular 8/94. London: DfE 8/94
[11] DfE (1994b) The Education of Pupils with Emotional and Behavioural Difficulties. Circular 9/94. London: DfE 9/94.

[12] DfES (2001) The Special Educational Needs: Code of Practice 2001. Nottinghamshire: Department for Education and Skills publications (DfES 581/2001) [Online]. Available from: http://www.teachernet.gov.uk/_doc/3724/SENCodeOfPrac tice.pdf [Accessed 10/10/08]

[13] Loizidou, H. P., Vlami, S., Nicolaidou, M. (2007) Evaluation of the Pilot Programme: Zones of Educational Priority (ZEP). Nicosia: Ministry of Education \& Culture and Pedagogical Institute of Cyprus. In Greek:

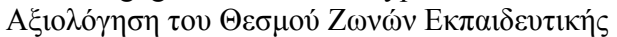

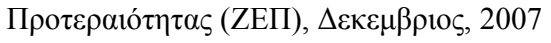

MOEC (1992) Information Booklet on Special Education: Circulars of the Ministry of Education and Culture for the provision of Special Education to children with Special

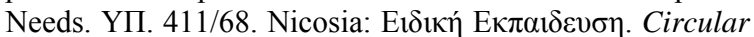
send to schools on $26^{\text {th }}$ May 1992 (regarding the provision of support towards children with special needs).

[14] MOEC (2008) Inclusion in the Cyprus Educational System at the beginning of the twenty first Century: An Overview. National Report of Cyprus. Nicosia: Ministry of Education and Culture Republic of Cyprus. November 2008. [Online]. Available from:

http://www.ibe.unesco.org/National_Reports/ICE_2008/cy prus_NR08.pdf From the Greek. [Access 18/08/09]

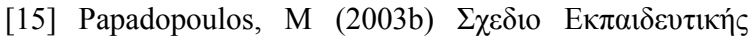

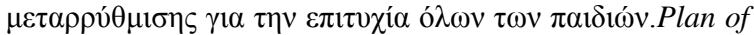
Educational Reformation for the Success of all pupils. Department of Educational Psychology- Ministry of Education and Culture. Limassol: Department of Educational Psychology (From the Greek).

[16] Rogers, B. (2005) "Chapter 15: Teaching Students with Emotional Behavioural Disorders." In: Clough, P., Garner, P., Pardeck, T.J., Yuen, F. (Eds) Handbook of Emotional and Behavioural Difficulties. London: Sage Publications Ltd

[17] Visser, J. (2005) "Chapter 14: Working with Pupils and Young people with Social, Emotional and Behavioural difficulties: What Makes What Works Work?" In: Clough, P., Garner, P., Pardeck, T.J., Yuen, F. (Eds) Handbook of Emotional and Behavioural Difficulties. London: Sage Publications Ltd

[18] Winzer, M. (2005) "Chapter 2: International Comparizons in EBD: Critical Issues." In: Clough, P., Garner, P., Pardeck, T.J., Yuen, F. (Eds) Handbook of Emotional and Behavioural Difficulties. London: Sage Publications Ltd. 